\title{
Minireview
}

\section{Allosteric activation of pyruvate decarboxylases. A never-ending story?}

\author{
Stephan König*, Michael Spinka, Steffen Kutter \\ Institute of Biochemistry and Biotechnology, Faculty for Life Sciences, Martin-Luther-University Halle-Wittenberg, Kurt-Mothes-Str. 3, 06120 Halle (Saale), Germany
}

\section{A R T I C L E I N F O}

\section{Article history:}

Available online xxx

\section{Keywords:}

Yeast enzymes

Thiamine diphosphate

Regulatory site

Conformation change

Activation kinetics

\begin{abstract}
A B S T R A C T
The allosteric substrate activation of pyruvate decarboxylases was studied for more than 30 years using varying techniques and ending up in different hypotheses on the molecular mechanism of substrate activation of this enzyme. Now, a number of high-resolution structures of the pyruvate decarboxylase species from Saccharomyces cerevisiae and from Kluyveromyces lactis - both wild type and variants in complex with covalently bound substrate or substrate surrogates - provided for the first time structural insights to decipher the mechanism of allosteric activation by describing the signal transduction pathway from the regulatory to the active site in detail. Here, the mechanistic studies on substrate activation of pyruvate decarboxylases are reviewed from a historical point of view, demonstrating that important parts of the different hypotheses got carried away with our new mechanism drawn from latest results of experiments on activation kinetics, small-angle X-ray solution scattering and X-ray crystal diffraction.
\end{abstract}

(C) 2009 Elsevier B.V. All rights reserved.

\section{Introduction}

Pyruvate decarboxylases (E.C.4.1.1.1) catalyse the non-oxidative decarboxylation of pyruvate yielding acetaldehyde and carbon dioxide. Together with the enzyme alcohol dehydrogenase (E.C.1.1.1.1), which reduces the acetaldehyde to ethanol with the help of the co-substrate NADH, it constitutes the metabolic pathway of alcoholic fermentation. PDC is localised in the cytosol of cells from yeasts, plant seeds and a few bacteria. In total, 32 gene sequences coding for PDC are deposited (Uni-ProtKB/Swiss-Prot), 18 from yeast, 13 from plants and one from bacteria. PDCs have been purified from all kinds of organisms mentioned above. Purification protocols were published for six species from ascomycetes [1-11], for five from plants [12-16], and for three species from bacteria [17-21]. The catalytic activity of PDC depends on the presence of the cofactor thiamine diphosphate (ThDP, Fig. 1), which is bound mainly via a divalent metal ion (magnesium in most cases) to the protein moiety (Fig. 2) at the interface of two subunits. The chemistry of ThDP catalysis is well understood from a considerable number of kinetic studies of enzyme variants [22-30] along with intermediate analyses [31-33] and studies of the effect of cofactor analogues [34-50]. Consequently a number of very detailed catalytic cycles for the PDC reaction have been proposed [28,30,32,39,51-60] (Fig. 3). Many detailed kinetic studies have been conducted on yeast PDC wild types. A number of ScPDC variants were analysed, too [6,24,28,29,53,57,58,61-64]. Some active

\footnotetext{
* Corresponding author. Tel.: +49 345 5524829; fax: +49 33455527014.

E-mail addresses: koenig@biochemtech.uni-halle.de (S. König),

mspinka@web.de (M. Spinka), steffen.kutter@student.uni-halle.de (S. Kutter).
}

site variants (E51A, D28A, E477Q) proved to be almost catalytically inactive. As early as in 1967 Davies [65] found a sigmoidal curvature in the $v v s$. [substrate] plot for the catalysed reaction of PDC from wheat. A similar kinetic behaviour was described for PDC from brewer's yeast (ScPDC) 3 years later [66-68]. As this kinetic phenomenon was induced by the substrate pyruvate itself, this behaviour was interpreted as allosteric substrate activation of PDC. The first quantitative kinetic analysis of this phenomenon was published in 1978 [69]. By using the stopped-flow technique it could be demonstrated that at substrate concentrations around $S_{0.5}$ (the equivalent value to $\left.K_{\mathrm{m}}\right)$ a considerable time period $(10-20 \mathrm{~s}$ at $30^{\circ} \mathrm{C}$ ) elapses before catalysis is accelerated and the final steady state is entered. Assuming a slow isomerisation step from an inactive to an activated enzyme state, it was possible to determine microscopic rate constants. The observed activation rate constant rises hyperbolically with increasing substrate concentration. In a detailed kinetic study on allosteric substrate activation of KlPDC, another yeast PDC, it was demonstrated that this dependence might be even more complex [9]. The existence of different and stable enzyme conformations - a catalytically inactive and an activated state - was proven by chemical cross-linking of ScPDC with bisimidates of varying chain lengths in the absence and the presence of the substrate pyruvate [70]. The yeast enzymes share their substrate activation behaviour with PDCs from plant seeds $[11,13,16,71]$. In contrast, the PDC from the bacterium Zymomonas mobilis (ZmPDC, [72]) and indolepyruvate decarboxylase from Enterobacter cloacae (EcIPDC, [73]) show Michaelis-Menten type kinetics without any sign of substrate activation. A number of substrate surrogates have been identified which are able to activate PDC as well.

The effects of pyruvamide (PA, Fig. 4) on the activation kinetics have been studied in detail for ScPDC [69] and for KlPDC [9]. 
<smiles>CC1=C(CO)C(=O)N1Cc1cnc(C)nc1N</smiles>

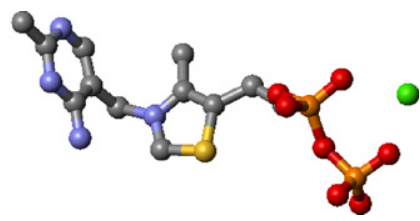

Fig. 1. Structure of the cofactor thiamine diphosphate. Left, chemical structure, the substrate binding site at the $\mathrm{C} 2$-atom is marked by a red asterisk; right, ball-andstick presentation of the crystal structure model of the cofactor representing the $\mathrm{V}$-conformation, carbon atoms are coloured in grey, nitrogens in blue, sulphur in yellow, phosphorous in orange and oxygens in red, the magnesium ion is shown in green. (For interpretation of the references to colour in this figure legend, the reader is referred to the web version of the article.)

Phosphonate analogues of pyruvate (among them methyl acetyl phosphonate, MAP) have been applied to elucidate the catalytic cycle [74-78] or to trap reaction intermediates in crystal structures [79-81]. Chemical modification of PDCs with group specific reagents pointed to an important role of cysteine residues [82]. The number and reactivity of cysteines was determined by modification with 4-hydroxy mercuribenzoate and 3-bromopyruvamide, respectively [83]. Site directed mutagenesis of cysteine residues and the determination of kinetic constants and solvent isotope effects for the corresponding variants demonstrated that modification of residue $\mathrm{C} 221$ should be the initial step of enzyme activation [61,84-85]. Furey et al. [86] recognized that C221 is located at a switch point of the middle (R-) domain of the subunit. However, the question remained, how the activating signal is transmitted from the regulatory to the active site. Kinetic studies on a number of variants, which were derived based on the crystal structure model of ScPDC crystallized in the absence of any activator, favoured a direct pathway through adjacent amino acid side chains to the cofactor ThDP $[57,63,64]$. On the basis of comprehensive analyses of $v v s$. [substrate] plots, Hill coefficients, and pH dependent kinetics of variants along the way, a signal transduction path was postulated, starting from C221 via H92, E91, and W412. The last residue is part of a loop (residues 410-415), which directly interacts with the cofactor ThDP. However, in 2006 Joseph et al. [53] mentioned for the first time that another flexible loop region (residues 288-304) might be involved in the signal transfer pathway.

PDCs are multi-subunit enzymes. The typical molecular mass of one subunit is $59-61 \mathrm{kDa}$. The tetramer is the catalytically active state of most PDCs. Higher oligomers (octamers) have been described for PDCs from plant seeds [13,16] or fungi [5]. However, studies on structure function relationships of yeast PDCs showed that the dimer is the minimum functional unit of the enzyme with considerable catalytic activity $[87,88]$. On the other hand, Furey et al. [89] postulated from the crystal structure model of ScPDC that allosteric activation requires a tetrameric structure. Only in this state the middle (R-) domain, which is very flexible and contains $\mathrm{C} 221$, can interact with other domains in other subunits.

The first crystal structure of a PDC species was published in 1993 [90] followed by others for KlPDC [91], for ScPDC activated by PA [7] and ketomalonate [89], respectively, and for two non-activated species, ZmPDC [92] and EcIPDC [93]. All of these structures display a very high similarity on the basis of monomers and dimers (for an early comparison see Muller et al. [94]) whether or not they are allosterically regulated. Monomers consist of three domains, each with an open $\alpha / \beta$ topology, 5-6 stranded $\beta$-sheets are surrounded by $\alpha$-helices (Fig. 5). Domains are connected by long, in some cases flexible loop regions. The cofactor ThDP is bound between two monomers. Each N-terminal (PYR-) domain binds the aminopy-

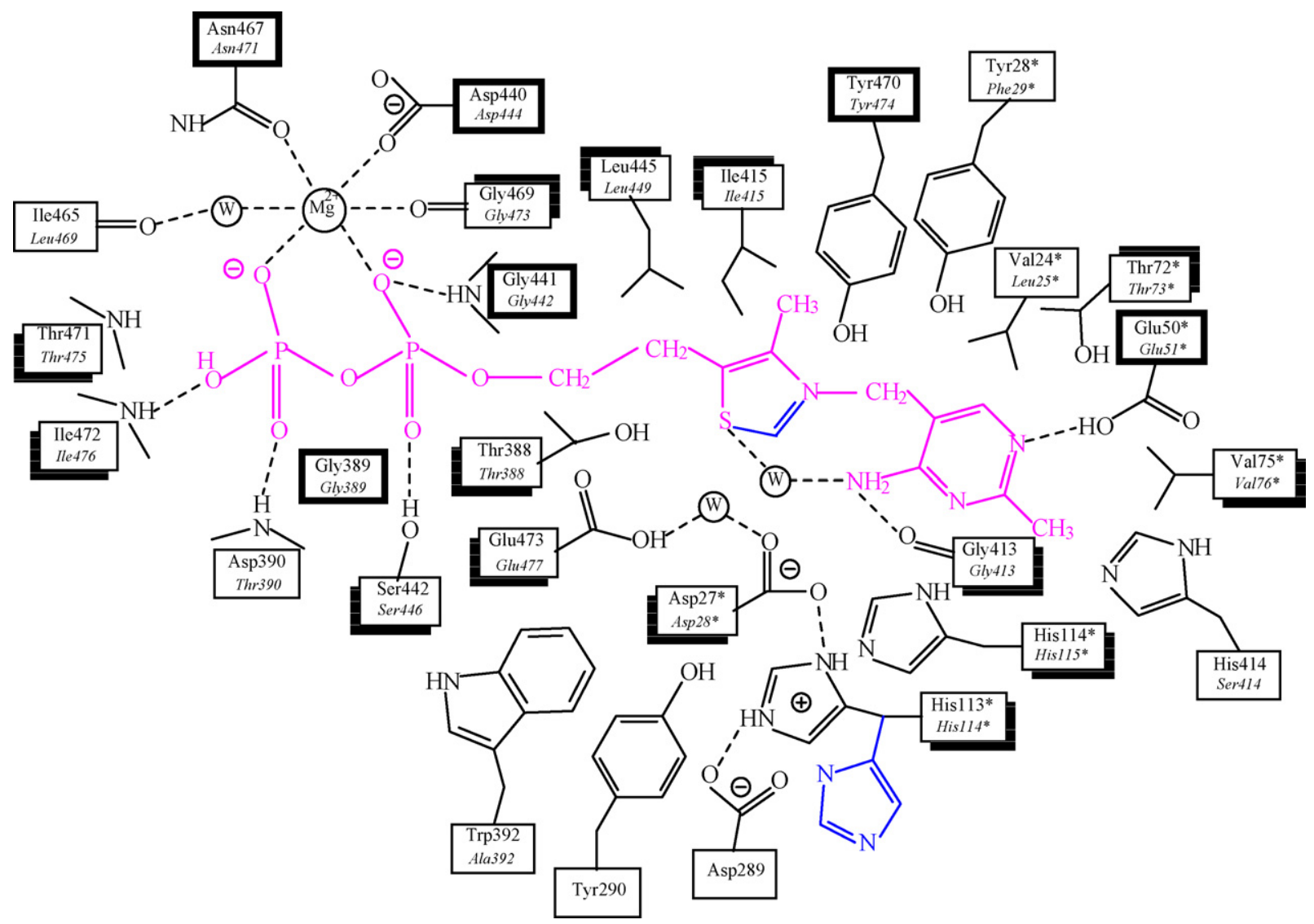

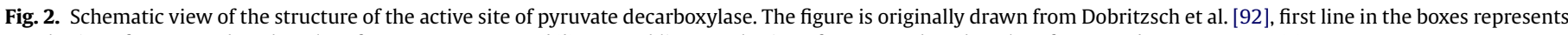
numbering of pyruvate decarboxylase from Zymomonas mobilis, second line numbering of pyruvate decarboxylase from Saccharomyces cerevisiae. 
<smiles>[R6]CCCC([R])=O</smiles><smiles>[R6]Cc1sc(C([R])([X])O)[n+]([PH3+])c1C</smiles>

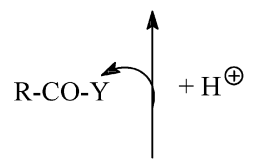

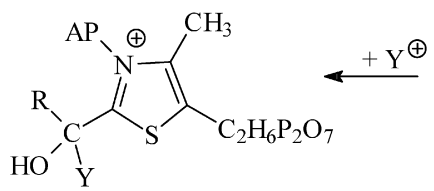<smiles>[R]C(O)=C1SC(C[R6](=O)OCC)=C(C)N1[Y7]</smiles><smiles>Cc1ncc(C)c(N)n1</smiles><smiles>CC(C)C1CC1</smiles><smiles>[R]C(=O)c1sc(C=[R6])c(C)[n+]1[PH3]</smiles>

AP

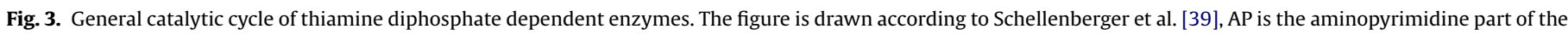
cofactor, in case of pyruvate decarboxylases $\mathrm{X}^{+}$is carbon dioxide and $\mathrm{Y}$ a proton.

rimidine part of the cofactor, each C-terminal (PP-) domain the corresponding diphosphate part via the divalent magnesium ion, generating the vital V-conformation of the cofactor ThDP [95]. The proposed ThDP binding motif is found in all PDCs analysed so far [96]. Because of this cofactor-binding mode, monomers are associated very tightly within one dimer resulting in large interface areas [92]. Significant differences between PDC crystal structures manifest themselves mainly at the tetramer stage. For instance, ScPDC without bound ligands [90] forms a planar tetramer arrangement (rotation angle of dimers $\sim 4^{\circ}$ ), whereas ScPDC crystallized in the presence of the substrate surrogate PA forms a half-side closed tetramer (rotation angle of dimers $\sim 30^{\circ}$, [7]). Furey et al. [89] found both states, half-side closed and planar dimer arrangement in ScPDC crystallized in the presence of ketomalonate (KM) (Fig. 6). Consequently, the twofold symmetry is lost within the tetramer. A half-side closed conformation was also found for KlPDC in the absence of any ligand [91]. The quaternary crystal structure of ZmPDC [92] and EcIPDC [93], the only<smiles>CC(=O)C(=O)[O-]</smiles><smiles>CC(=O)C(N)=O</smiles><smiles>COP(=O)([O-])C(C)=O</smiles>

Pyruvate
Pyruvamide (PA) Methyl acetylphosphonate (MAP)<smiles>CC(O)(S[Ge])C(=O)[O-]</smiles>

Thiohemiketal of pyruvate and cysteine

Fig. 4. Chemical structures of the activators pyruvate, pyruvamide, and methyl acetyl phosphonate together with structure of the thiohemiketal resulting from the nucleophilic attack of the thiol group of cystein on the $\mathrm{C} \alpha$-atom of pyruvate. species without allosteric activation, display an almost rectangular arrangement of the dimers within the tetramers (rotation angle $78^{\circ}$ and $90^{\circ}$, respectively) with considerable larger dimer-dimer interfaces compared to the allosteric activated species (Fig. 7). This correlates to a higher rigidity of the former. However, the mode of tetramer arrangement does not appear to be the critical feature of the activation mechanism. Instead, it is the flexibility of two loop regions near the catalytic site of PDC, which is different for the activated and non-activated enzyme species. These loop regions, comprising residues 104-113 and 288-304 (identical numbering for KlPDC and ScPDC), had never been detected in crystal structures of yeast PDCs crystallized in the absence of activators, due to their inherent disorder [90,91]. However, in the crystal structure of PA activated ScPDC [7], they become at least ordered at the closed side of the tetramer. Only at this side, PA molecules are bound at regulatory sites and active sites. This ligand binding should affect the efficiency of catalysis by initiating conformational changes of the protein structure. Interestingly, further refinement of the experimental data of KIPDC crystallized in the absence of activators [91] to $1.95 \AA$ resolution allowed to trace the residues 104-115 also in this structure of the non-activated state, but still with high temperature factors (unpublished results). Changes of the dimer arrangement within tetramers have been observed for the first time directly in SAXS studies. The presence of PA in enzyme solutions led to a significant increase of the radius of gyration $\left(R_{\mathrm{G}}\right.$, the scattering parameter describing the maximum distance of two points within a particle in solution) in the corresponding scattering patterns [97]. This result suggested a global conformational change of the enzyme molecule in solution without altering the oligomerisation state (because of the unchanged scattering intensity $I(0)$, which scales with the molecular mass of the particle). The crystal structure of PA activated ScPDC confirmed these changes [7]. The binding of the activator at the regulatory site of the enzyme caused a rotation of the two dimers relative to each other within the tetramer resulting in the half-side closed conformation mentioned above. However, 

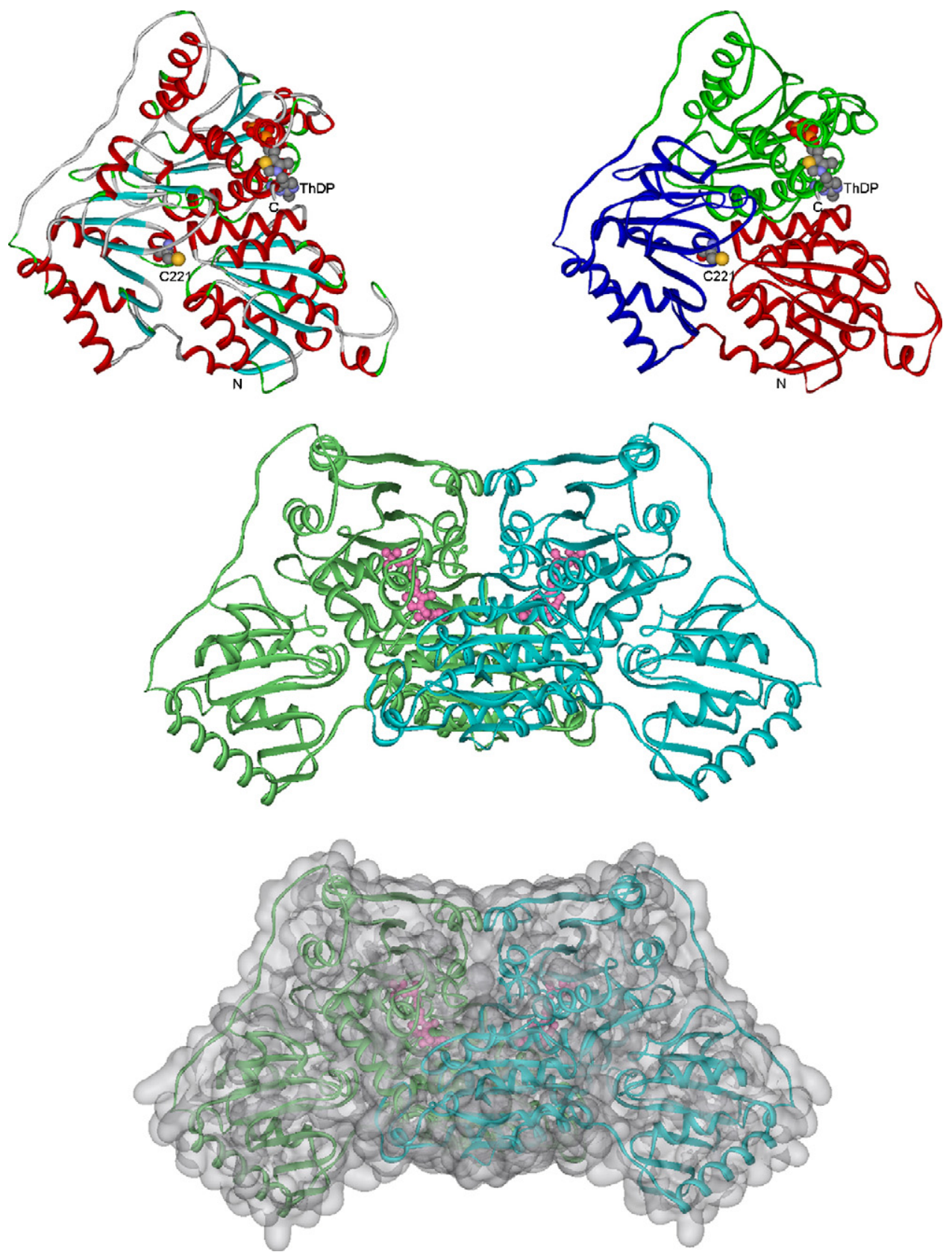

Fig. 5. Solid ribbon model of the crystal structure of the monomer and dimer of pyruvate decarboxylases. Upper panel: monomer, left, colouring according to the secondary structure, helices in red, $\beta$-strands in light blue, $\beta$-turns in green and loops in light grey; right, colouring according to the $\alpha / \beta$-domains, $\mathrm{N}$-terminal domain, red, middle domain, blue, C-terminal domain, green, the cofactor thiamine diphosphate and residue C221 are presented in space filling mode with the atomic colour code of Fig. 1, the $\mathrm{N}$-terminus and the C-terminus are illustrated, lower panels, monomer arrangement within the functional dimer, the orientation of the light green monomer is the same as above, the symmetry related monomer is shown in light blue, thiamine diphosphate in magenta, the surface of the dimer is overlaid in light grey. (For interpretation of the references to colour in this figure legend, the reader is referred to the web version of the article.)

PA was found in half of the regulatory and active sites only and not directly bound to C221, but $10 \AA$ away instead. Consequently, only half of the flexible loop regions became ordered.

Although kinetic studies on PDCs with changes at residue C221 (i.e. genetically engineered or chemical modified) pointed to covalent binding of the substrate in the process of allosteric activation the corresponding adducts have not been found in PDC crystal structures using the substrate surrogates KM or PA. This situation resulted in different hypotheses on the signal transduction pathway, one postulating direct interactions of amino acid residues $[57,63,64]$ and the other postulating concomitant local (loop structuring) and global (dimer reorientation) conformation changes [7].

\section{Results and discussion}

Several new crystal structures of PDCs with covalently bound substrate or substrate surrogate (MAP-KIPDC, PA-ScPDC $\mathrm{E} 477 \mathrm{Q}_{\text {, PYR- }}$ $S_{C P D C}{ }_{\mathrm{D} 28 \mathrm{~A}}$, and PYR-SCPDC $\mathrm{E}_{477 \mathrm{Q}}$ ) have been obtained. Together with results on detailed activation kinetics of these complexes and direct ligand binding studies using SAXS it is now possible to describe the mechanism of allosteric activation of PDCs comprehensively.

\subsection{Kinetic effects of activators}

The activating effect of the activators PYR and PA on PDC has been demonstrated in detail previously $[9,69,71]$. As illustrated in 

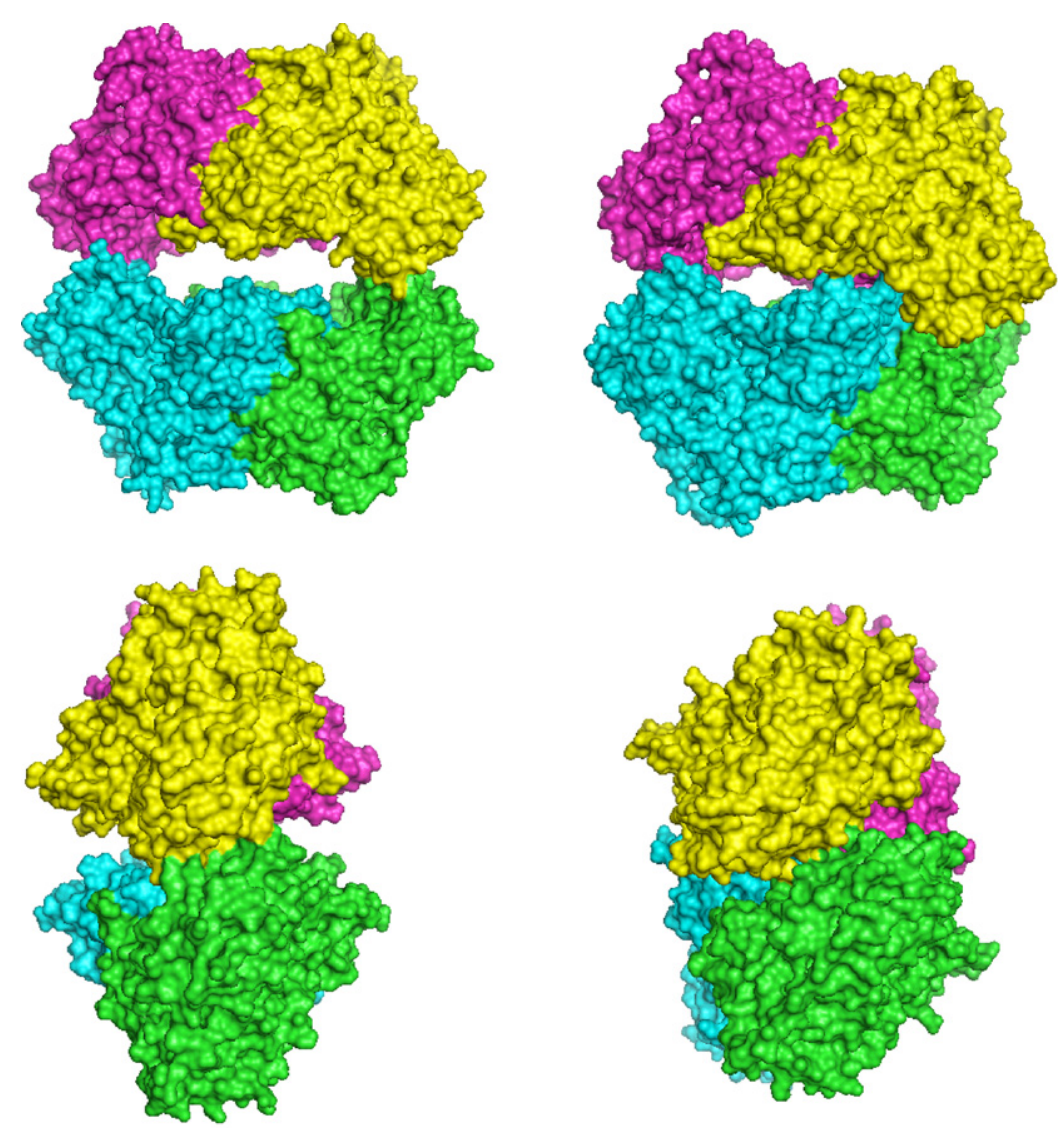

$S c P D C$

MAP-KlPDC

$K l \mathrm{PDC}$
$\mathrm{PA}-S c P D C$
KM-ScPDC

PA-ScPDC $\mathrm{E}_{7770}$

PYR-ScPDC $C_{D 28 \mathrm{~A}}$

PYR-ScPDC $E 4770$

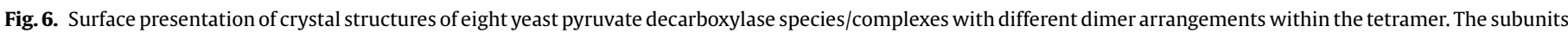

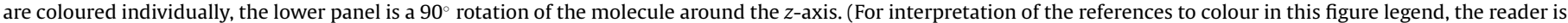
referred to the web version of the article.)

Fig. 8 the presence of MAP decreases the sigmoidicity of the $v v s$. [substrate] plot of KlPDC, too. After preincubation with MAP at a concentration of $75 \mathrm{mM}$ the enzyme's steady state kinetics is essentially hyperbolic. The ratio of initial rates $\left(v_{0}\right)$ and steady state rates $\left(v_{\mathrm{SS}}\right)$, evaluated from empirical progress curves, demonstrates that MAP is able to completely activate KlPDC. This is in contrast to the effect of PA with a maximum value of 0.65 for $v_{0} / v_{\mathrm{SS}}$.

\subsection{Direct activator binding studies using SAXS}

Addition of high concentrations of PA to ScPDC solutions resulted in a significant increase of the radius of gyration $\left(R_{\mathrm{G}}\right)$, interpreted as global rearrangement (dimer rotation) of the protein molecule [97]. The activator concentration dependence of $R_{\mathrm{G}}$ for the binding of PA and MAP to KlPDC and of PYR to $S C P D C_{E 477 Q}$ illustrates a clear saturation of the ligand binding (Fig. 9). Midpoint values for saturation $\left(S_{0.5}\right)$ can be drawn directly from sigmoid fits of the experimental data, $6 \mathrm{mM}$ for PYR, $22 \mathrm{mM}$ for MAP and $31 \mathrm{mM}$ for PA. As expected, the highest affinity is found for the natural substrate PYR. The lowest shift was found after binding of PA while the $R_{\mathrm{G}}$ increase for MAP comes close to the value for PYR. Notably, the values for the binding affinities drawn from activation kinetics and SAXS binding studies, respectively, conform closely to each other indicating that both methods monitor the same process.

\subsection{Crystal structures of MAP-KIPDC, PA-SCPDC $C_{E 477 Q}$, $P Y R-S C P D C_{D 28 A}$, and PYR-SCPDC $C_{E 477 Q}$}

\subsubsection{Overall structures}

The crystal structures of the complexes were determined to reasonable high resolutions of $1.4-2.3 \AA$ (for data collection, processing and refinement statistics see Kutter et al., doi:10.1074/jbc.M806228200, pdb id, 2vjy, 2w93, 2vk1, 2vk8). The asymmetric units contain the PDC tetramer. The final models comprise all 563 amino acid residues (except for residues 289-302 of one subunit of PA-SCPDC $\mathrm{E}_{477 \mathrm{Q}}$ ) of the monomer chain, besides the $\mathrm{N}$-terminus. Each of the subunits contains one cofactor molecule ThDP and one magnesium ion. In addition activator molecules, MAP, PA or PYR, are covalently bound at the regulatory sites and at the active sites of the enzymes (Fig. 10). In MAP-KIPDC and PYR-SCPDC ${ }_{\mathrm{D} 28 \mathrm{~A}}$ all sites are occupied. However, pyruvate molecules could not be detected at the active sites of $S C P D C_{E 4770}$, which should be associated with the disrupted cofactor molecule in this complex. In PA-SCPDC $447 \mathrm{Q}$ activator molecules are bound in both sites of two subunits. The occupancy in the other subunits is significantly lower. The overall folds of the subunits within one dimer are almost identical to that of the crystal structures of the corresponding species without bound activators (Fig. 5) (r.m.s.d. of $0.96-2.28 \AA$ for 1074 superimposed $(\alpha$-atoms). Significant differ- 


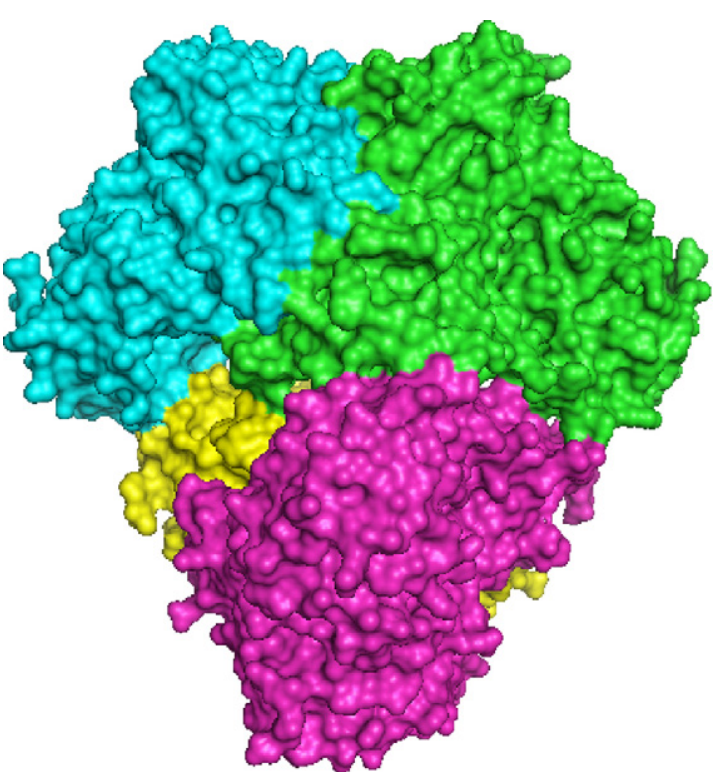

Fig. 7. Surface presentation of the crystal structure of the tetramer of indolepyruvate decarboxylase from Enterobacter cloacae for sake of comparison only. The subunits are coloured individually. This tetramer arrangement is never reached in the activated structures. (For interpretation of the references to colour in this figure legend, the reader is referred to the web version of the article.)

ences between activator-enzyme complexes and free enzymes were observed at the surface of the tetramer, i.e. at the helices 195-210, and 330-340, at the loop 340-356 and at the C-terminal helix. The tetramers of all four PDC complexes are superimposable without significant differences (r.m.s.d. of 0.5-0.6 ̊̊ for 2248 C $\alpha$-atoms).

The distances of the corresponding $\mathrm{C} \alpha$-atoms of the activator molecules to the C2-atom of ThDP at the active site and to the sulphur atom of $\mathrm{C} 221$ at the regulatory site fall into the range of 1.7-2.2 A. Some distances are too long for typical C-C-bonds and $\mathrm{C}-\mathrm{S}$-bonds, respectively. This could be indicative of a dynamic equilibrium of non-covalently and covalently bound activator. On the other hand, the covalent nature of the bonds is clearly demonstrated by the $\mathrm{sp}^{3}$ hybridisation of the corresponding $\mathrm{C} \alpha$-atoms of all activators (Fig. 10). In case of PA the amide carbon is $\mathrm{sp}^{3}$ hybridised, too. The additional electron density was interpreted as a hydroxyl group. The bound activator molecules are stabilized by interactions with a number of polar amino acid residues in the neighbourhood, $\mathrm{H} 92, \mathrm{H} 225$, and $\mathrm{H} 310$ at the regulatory site and D28, H114, and H115 at the active site.

\subsubsection{Loop structuring}

The most important feature common to all activated structures described herein is the well-defined electron density for two loop regions (residues 104-113 and 288-304, respectively, Fig. 11), which in contrast is poorly defined in crystal structures of nonactivated yeast PDCs $[90,91]$. Structuring and translocation of both loop regions is the result of a network of interactions induced by covalent binding of activator molecules at C221, the regulatory site of the enzyme. The originally flexible R-domain becomes fixed, which engenders interactions between this domain, both loop regions and the C-terminal helix. It may therefore be postulated that this network of new, activator induced interactions recognizable as loop structuring and loop translocation are the decisive events in the activation process. The gained rigidity of the domains at all subunits within the tetramer enforces the planar and symmetric dimer arrangement. Both loops are located in the neighbourhood to the active site (Fig. 11). In the frozen state these loop regions are stabilized internally by a number of $\mathrm{H}$-bonds.
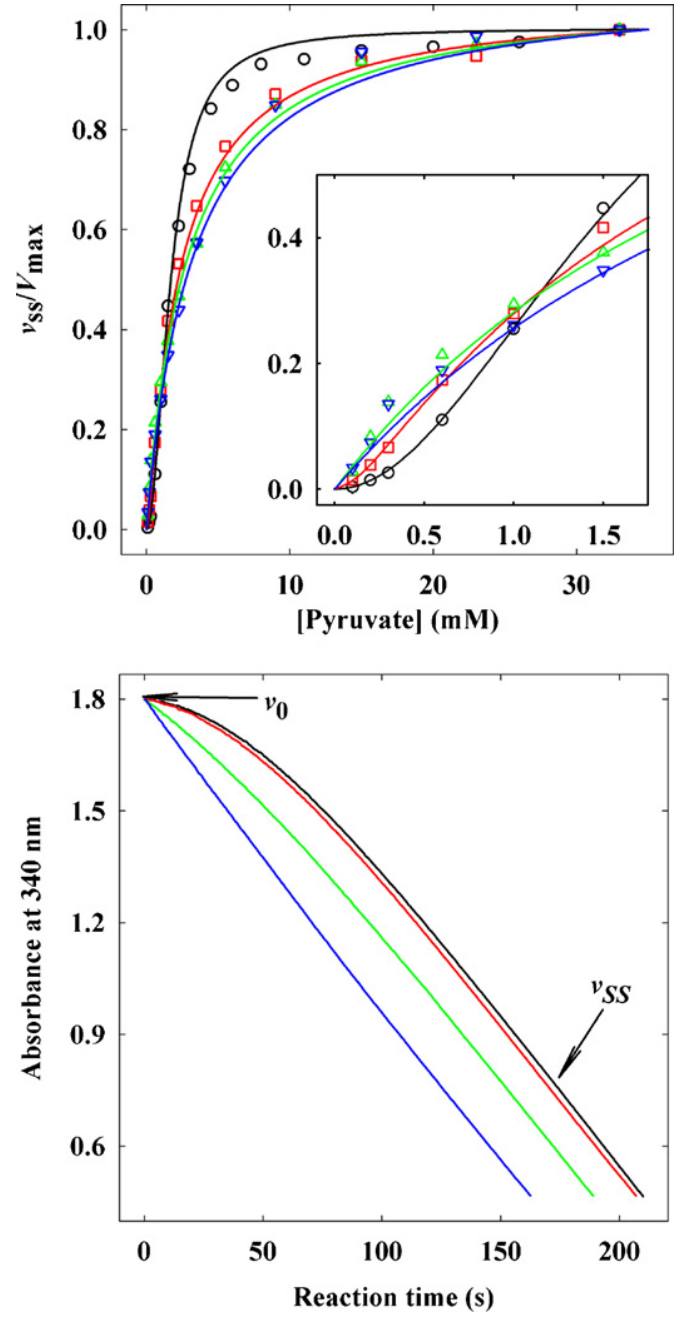

Fig. 8. Kinetics of the pyruvate decarboxylase (KlPDC) catalysed reaction in the presence of the activator methyl acetyl phosphonate (MAP). Upper panel, plot of relative reaction rate $v s$. substrate concentration, $0 \mathrm{mM}$ MAP, black circles, $20 \mathrm{mM}$ MAP, red squares, $40 \mathrm{mM}$ MAP, green triangles, $75 \mathrm{mM}$ MAP, blue inverse triangles, symbols, experimental data, lines, fit of the data, black and red, according to the simple equation for substrate activation [9], blue and green, hyperbola, inset, enlargement for low substrate concentrations, lower panel, transients of the catalysed reaction, same colour code as above, $v_{0}$, initial velocity as slope at the beginning of the reaction, $v_{\mathrm{ss}}$ steady state velocity at the linear part of the transients. (For interpretation of the references to colour in this figure legend, the reader is referred to the web version of the article.)

Loop 104-113 additionally develops a short $\alpha$-helix and closes partially over the active site. H114 and H115, the next upstream neighbours of loop 104-113, are part of the active site. Especially for H114 an essential function in PDC catalysis has been proposed from kinetic studies on accordant variants from yeast and bacteria [22,28-30]. Tittmann et al. [32] postulated a specific role for H114 (together with D28) during release of the reaction product acetaldehyde.

\subsubsection{Effects on the active site}

Interestingly, almost all side chains constituting the active site apart from D28, H114 and H115 remain unaffected by the binding of the activators at C221. Furthermore, no significant distortion of the cofactor's vital V conformation is seen in the activated state. However, a comparison of the non-activated and the MAP-activated crystal structures of KIPDC revealed that the two amino acids H114 and H115 undergo marked structural reorientations upon activator binding (Fig. 12). In the activated state, the 


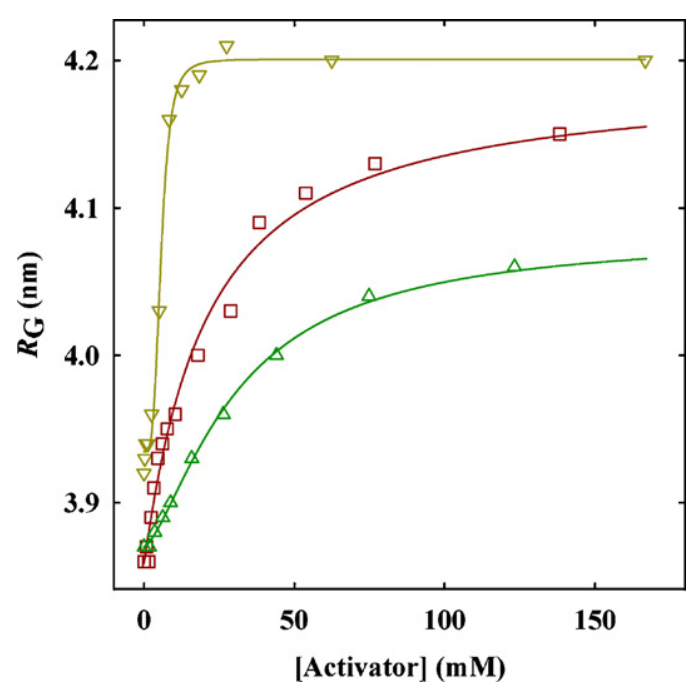

Fig. 9. Dependence of the scattering parameter radius of gyration $\left(R_{\mathrm{G}}\right)$ of yeast pyruvate decarboxylases on the activator concentration. PA binding at KlPDC, green triangles, MAP binding at KlPDC, red squares, PYR binding at $S c P D C_{D 28 A}$, yellow, symbols, experimental data, lines, sigmoid fits. (For interpretation of the references to colour in this figure legend, the reader is referred to the web version of the article.) histidine side chains are directed towards the substrate-binding site, i.e. the distances of their ring nitrogens to the $\mathrm{C} 2$ atom of the cofactor ThDP are diminished from 12-16 to 5.5-7.5 ̊. In one subunit of the native KIPDC tetramer, H114 and H115 are already orientated towards ThDP. Close inspection of the crystal structures relates this particular "activated" subunit to crystal contacts of its respective R-domain to neighbouring tetramers. Concomitantly, the side chain of D28 is rotated $\sim 35^{\circ}$ towards H115. These reorientations basically restructure the active site into its enzymatically competent architecture-triggered by covalent activator binding at C221.

\subsubsection{Signal transfer from the thiohemiketal at $\mathrm{C} 221$ to the active site}

Two pathways have been postulated for signal transfer during allosteric enzyme activation, a direct pathway starting from C221 via H92, E91, and W412 to the substrate binding site at ThDP $[57,63,64]$, and an indirect way, where activator binding induces a network of new interactions between different domains resulting in a more rigid tetramer structure and fixation of two loop regions, first proposed by Lu et al. [7] in 2000. However, the new structural insights now allow a more detailed description of this pathway. The trigger of the allosteric activation process is indeed the binding of an activator molecule at the regulatory site at residue C221. Three histidine residues (H92, H225, and H310) align the activator,
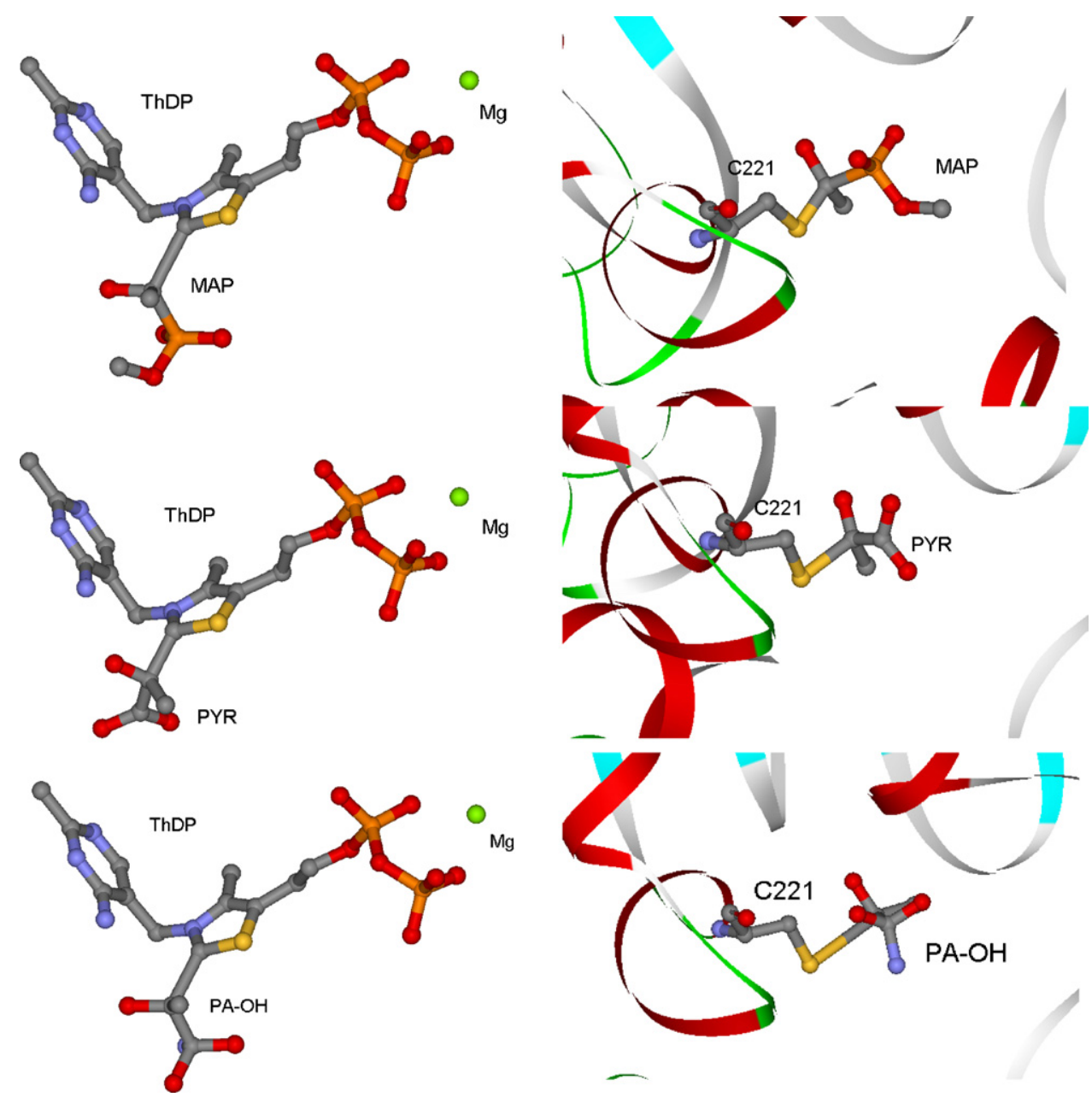

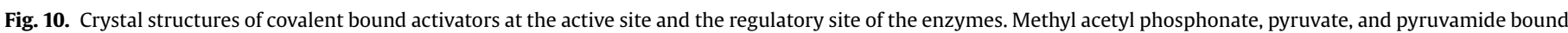

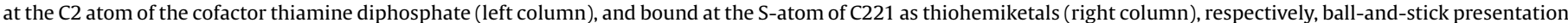

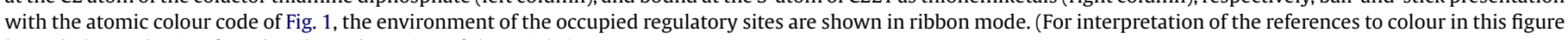
legend, the reader is referred to the web version of the article.) 

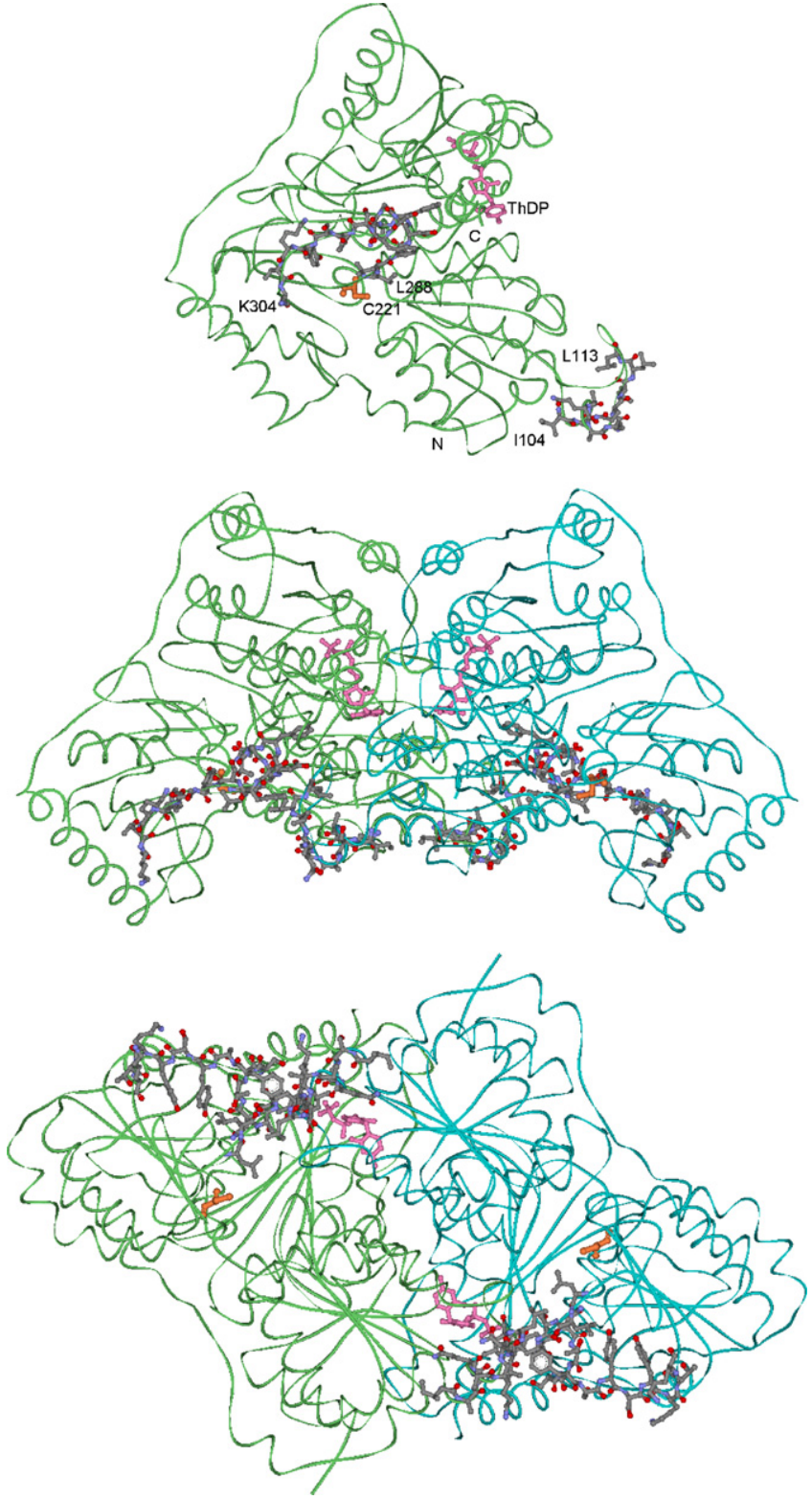

Fig. 11. Localisation of the loop regions 104-113 and 288-304 within the crystal structure of yeast pyruvate decarboxylase monomers (upper panel) and dimers (lower panels). The whole structure is presented in ribbon mode, residue C221 (orange), the loop residues (atomic colour code of Fig. 1) and thiamine diphosphate (magenta) are shown as ball and sticks, $\mathrm{N}$-terminus and C-terminus are indicated, the lower dimer results from a $90^{\circ}$ rotation around the $y$-axis. (For interpretation of the references to colour in this figure legend, the reader is referred to the web version of the article.)

promoting the formation of a thiohemiketal (Figs. 4 and 10). The covalent modification of C221 causes a $4 \AA$ shift of its side chain, and in case of SCPDC an additional rotation by $33^{\circ}$. This conformation change enforces the reorientation of a number of amino acid residues in the interaction radius of the thiohemiketal, such as H92, H225, G286, A287, H310, and S311 (Fig. 13). The emerging interaction network fixes the complete R-domain (24\% decrease of the overall B-factors). Loop 288-304 is part of that domain and is completely restructured. This loop forms a number of interactions with the other, originally flexible loop 104-113 of the PYR-domain, especially via residues L289, S290, and D291 interacting with residues L112, L113. In turn, the loop 104-113 also becomes structured itself. Further stabilization of the loop 104-113 arises from interactions
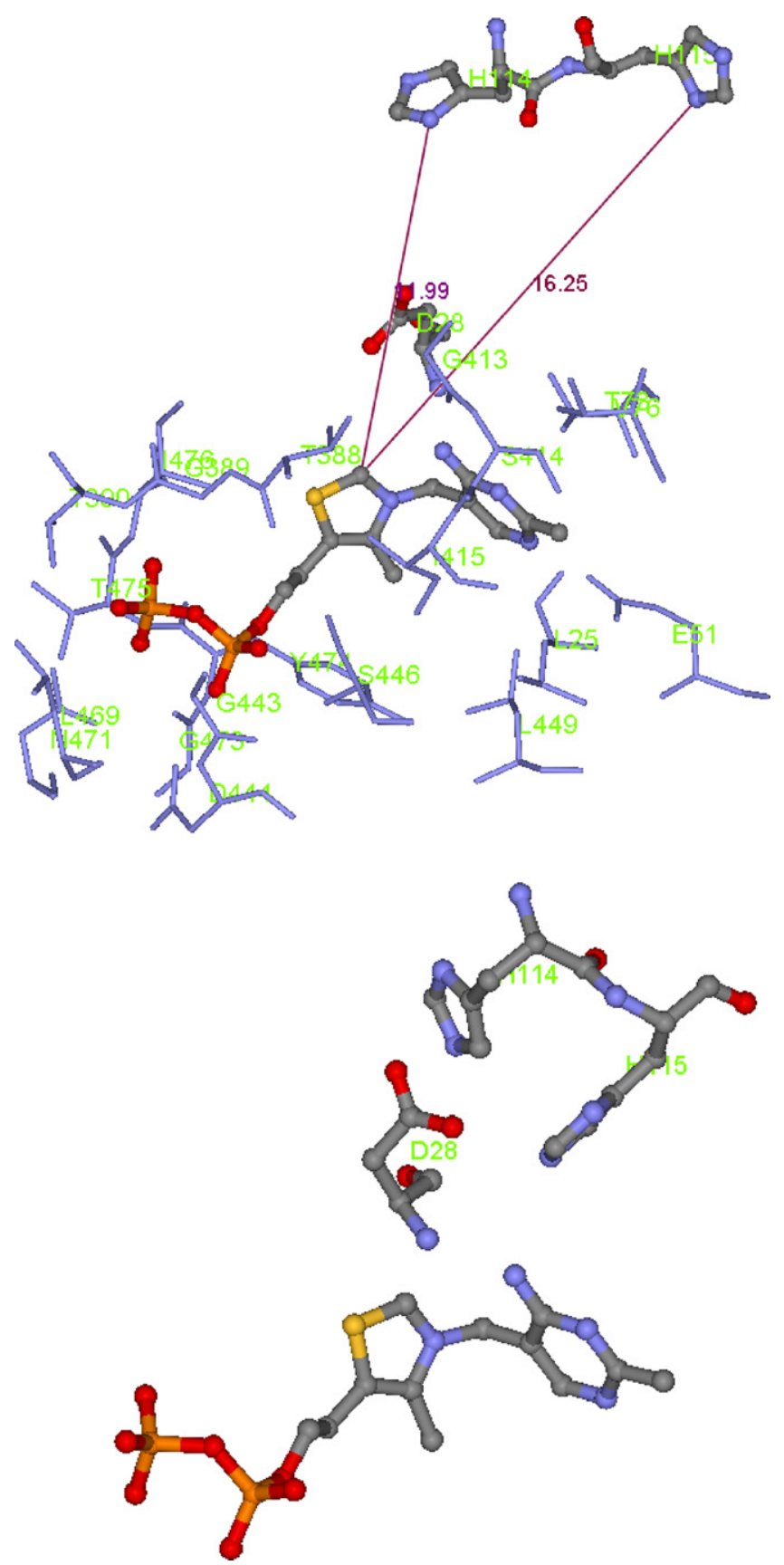

Fig. 12. Different orientation of side chains of H114, H115, and D28 at the active site of pyruvate decarboxylase (KlPDC). Upper panel, conformation of side chains in the absence of activator, additional to H114 (12 Å distance), H115 (16 Å distance), and D28, all side chains of amino acids surrounding thiamine diphosphate are illustrated in stick mode (in correspondence to the residues shown in Fig. 2), lower panel, side

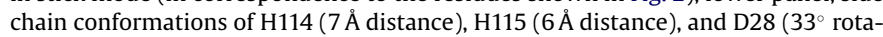
tion) in the crystal structure of MAP-KIPDC. The MAP molecule has been omitted for the sake of clarity.

with the C-terminal helix, which now closes over the active site. The position of the latter is now identical to its counterpart in the threedimensional structures of the permanently active species $Z \mathrm{mPDC}$ and EcIPDC (Fig. 7). Eventually, the signal is transmitted to the active site of the enzyme. H114 and H115, the adjacent residues to loop 104-113, are shifted and orientated towards the thiazolium ring of ThDP. The methyl group of residue D28 is rotated by $35^{\circ}$. This new arrangement of amino acid residues at the active sites allows direct interaction with the substrate binding at the $\mathrm{C} 2$-atom of the cofac- 


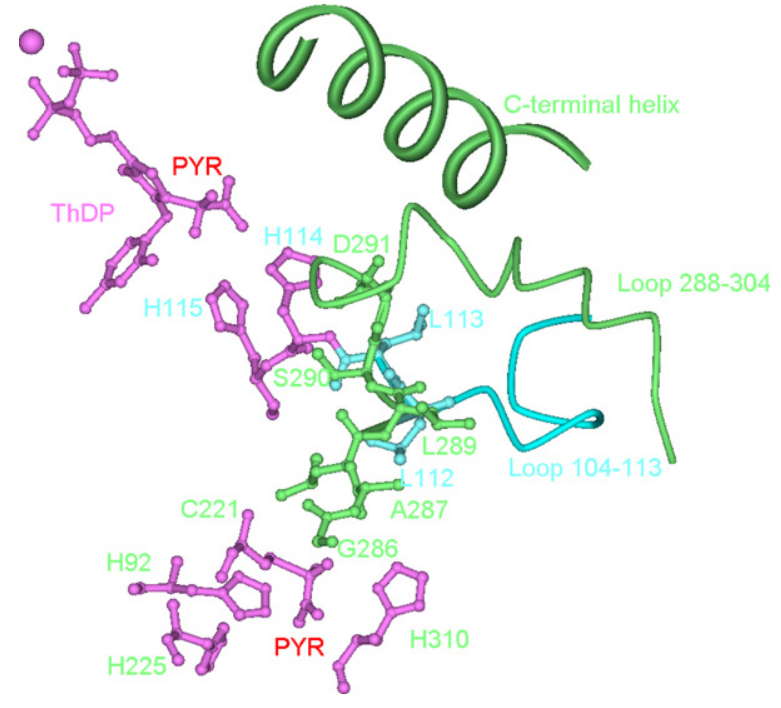

Fig. 13. Signal transduction pathway of allosteric activation of yeast pyruvate decarboxylases. Only those parts around one active site of the crystal structure of PYR-SCPDC $C_{D 28 A}$ are illustrated, which undergo significant conformation changes during enzyme activation. Amino acid side chains are shown as ball and sticks, secondary structure elements as tubes, active site and regulatory site in magenta, residues of different monomers within the functional dimer in light green and light blue, respectively. (For interpretation of the references to colour in this figure legend, the reader is referred to the web version of the article.)

tor and in this way a substantial acceleration of enzyme catalysis (Fig. 12). Notably, residues E91, and 410-413 proposed as part of the signal transduction pathway by Baburina et al. [57] and Li et al. [63] do not experience any displacement or change of flexibility in the activated structures. As described above, a network of new interactions is created until the activated state is fixed. Thus, the whole enzyme molecule is involved in these conformation changes. Some amino acids might be shifted in the transition state of activation, but essentially relax to their original position after the process is completed. Therefore, the amino acids shown to be relevant for activation by extensive kinetic and spectroscopic studies [28,57,61,63] keep on playing their part.

\section{Conclusions}

\subsection{Allosteric enzyme activation and activation of the cofactor ThDP}

A decade ago, Kern et al. [31] have shown that one prime molecular target of activation in ScPDC is the deprotonation at the $\mathrm{C} 2$ atom of ThDP, which requires a tremendous shift of the $\mathrm{p} K_{\mathrm{a}}$ value of the C2 proton to become catalytically competent [98]. The structural basis of this kinetic effect remained, however, largely elusive. Evidently, some structural differences between the active sites in the native and the activated state must account for the observed acceleration of the H/D exchange at the cofactor's C2 atom as triggered by activation in all yeast PDCs. The results of the current crystallographic studies allow some preliminary insight. The active site is complete only in the activated state. Side chains of amino acid residues, which are important for catalysis, as D28 and H114 are reoriented towards the substrate-binding site at the $\mathrm{C} 2$ atom of ThDP during enzyme activation. The structured loops 104-113 and 288-304, shield the active site against the solvent together with the C-terminal helix. The resulting less polar environment dramatically promotes deprotonation at the $\mathrm{C} 2$ atom of the cofactor [99]. Solvent shielding might also contribute to the stabilization of non-polar reaction intermediates as e.g. the enamine.

\subsection{Different dimer arrangements within $P D C$ tetramers-comparison of results from crystal diffraction and solution scattering}

As mentioned above, only two types of dimer arrangement have been found in eight crystal structures of yeast PDCs, the open and planar tetramer and the half-side closed tetramer with tilted dimers (rotation angle $\sim 30^{\circ}$ ) (Fig. 6). However, the occurrence of both types does not correlate with the activation state of the enzymes in the crystal. The tetramer structure of non-activated ScPDC [90] is planar, that of KlPDC [91] is half-side closed. The tetramers of the four activated crystal structure complexes described herein are planar. The tetramers of the previously published crystal structures of PAactivated ScPDC [7] and one form of KM-activated ScPDC [89] are tilted. The dimer arrangement in the crystals is independent either of the enzyme species (ScPDC, KlPDC) or of the activator (PYR, PA, MAP, KM). The activator PA (KM could not be traced because of low resolution) was merely non-covalently bound both at the active sites and at the regulatory sites, here some $10 \AA$ away from the thiol group of C221 [7]. Only the activator binding sites at the closed side of the tetramer were occupied. For PA-SCPDC $\mathrm{E}_{477 \mathrm{Q}}$ a planar dimer arrangement was found with covalently bound activator molecules. However, even in this structure only half of the binding sites are occupied. The results of the kinetic and SAXS studies described herein, clearly demonstrated the lower activation capability of the activator PA. The appearance of both tetramer conformations in non-activated species (ScPDC - planar, KlPDC - half-side closed) may point to conformation equilibria of PDC tetramers in solution and to differing crystal contacts in the solid state.

Despite the different conformations found in the crystal structures the SAXS studies illustrate a more consistent situation of the effect of activator binding in enzyme solutions. The concentration dependent increase of the $R_{\mathrm{G}}$ values for all the PDC species and activators indicate an expansion of the conformation during the activation process, again with varying effects of the corresponding activators (Fig. 9). This expanded conformation in solution may correspond to the planar conformation found in the new crystal structures of the activator-enzyme complexes, while the more compact structures should relate to the half-side closed conformation.

\subsection{Kinetic reflections from a crystallographic point of view}

The original kinetic scheme describing the activation of yeast PDC as proposed by Hübner et al. [69] in the precrystallographic era of ThDP research and substantiated by subsequent work $[100,101]$ involves only one type of independent subunits. As it completely neglects the oligomeric character of the enzyme it excludes cooperative interactions between subunits or active centres by definition. Nevertheless it fits the empirical kinetic data fairly well. Therefore a few comments as to whether the Hübner model comes close to reality in the light of crystallographic evidence might be in place. Obviously, the minimum functional unit of ScPDC is the dimer as the ThDP molecule is bound at the interface of two monomers. The dimer is active and shows allosteric regulation [87,88]. Each tight dimer contains two active sites as well as two regulatory sites. The signal transfer pathway presented above implies that the activating signal emanating from a given regulatory centre traverses the boundary of two subunits within the tight dimer via the interaction of the loop 288-304 (of the subunit harbouring the covalently modified Cys221) with the loop 104-113 of the other subunit. Finally His114 and His 115 are shifted, completing an active site whose pyrophosphate-binding region belongs to the very same subunit, which harbours the liganded cysteine. Thus, each C221 communicates with its "own" active centre, although this communication is partly mediated by structural elements of the other 
subunit (Fig. 13). From the crystallographic point of view there are no indications that ligand binding at one regulatory site affects the properties of more than one active site. Thus each active site can be probably activated independently. Moreover, NMR data on the H/D exchange at the $\mathrm{C} 2$ atom of the cofactor in SCPDC does not support any cross talk between active centres either [31,32]. This essentially justifies the original idea underlying the model of Hübner et al. [69] that portrays SCPDC as a hysteretic enzyme in the sense of Frieden [102]. A potential objection could be the fact that PA cannot completely activate yeast PDC, which suggests the existence of negative cooperativity.

\section{References}

[1] T. Ozawa, Y. Satou, I. Tomita, Vitamins 45 (1972) 22-29.

[2] R. Ludewig, A. Schellenberger, FEBS Lett. 45 (1974) 340-343.

[3] B.C. Farrenkopf, F. Jordan, Prot. Expr. Purif. 3 (1992) 101-107.

[4] M. Sieber, S. König, G. Hübner, A. Schellenberger, Biomed. Biochim. Acta 42 (1983) 343-349.

[5] M.E. Alvarez, A.L. Rosa, E.D. Temporini, A. Wolstenholme, G. Panzetta, L. Patrito, H.J.F. Maccioni, Gene 130 (1993) 253-258.

[6] M. Killenberg-Jabs, S. König, S. Hohmann, G. Hübner, Biol. Chem. Hoppe-Seyler 377 (1996) 313-317.

[7] G. Lu, D. Dobritzsch, S. Baumann, G. Schneider, S. König, Eur. J. Biochem. 267 (2000) 861-868.

[8] F. Neuser, H. Zorn, U. Richter, R.G. Berger, Biol. Chem. 381 (2000) 349-353.

[9] F. Krieger, M. Spinka, R. Golbik, G. Hübner, S. König, Eur. J. Biochem. 269 (2002) 3256-3263.

[10] Q.H. Wang, P. He, D. Lu, A. Shen, N. Jiang, J. Biochem. 136 (2004) 447-455.

[11] S. Acar, M. Yucel, H. Hamamci, Enzyme Microb. Technol. 40 (2007) 675682.

[12] K. Oba, I. Uritani, J. Biochem. 77 (1975) 1205-1213.

[13] H. Zehender, D. Trescher, J. Ullrich, Eur. J. Biochem. 167 (1987) 149-154.

[14] S. Leblova, L. Martinec, Biologia (Bratislava) 42 (1987) 1181-1189.

[15] J. Rivoal, B. Ricard, A. Pradet, Eur. J. Biochem. 194 (1990) 791-797.

[16] U. Mücke, S. König, G. Hübner, Biol. Chem. Hoppe-Seyler 376 (1995) 111117.

[17] T.C. Hoppner, H.W. Doelle, Eur. J. Appl. Microbiol. Biotechnol. 17 (1983) 152-157.

[18] G. Miczka, J. Vernau, M.R. Kula, B. Hofmann, D. Schomburg, Biotechnol. Appl. Biochem. 15 (1992) 192-206.

[19] S.E. Lowe, J.G. Zeikus, J. Gen. Microbiol. 138 (1992) 803-807.

[20] L.A. Talarico, L.O. Ingram, J.A. Maupin-Furlow, Microbiology 147 (2001) $2425-2435$.

[21] K.C. Raj, L.O. Ingram, J.A. Maupin-Furlow, Arch. Microbiol. 176 (2001) $443-$ 451.

[22] J.M. Candy, J. Koga, P.F. Nixon, R.G. Duggleby, Biochem. J. 315 (1996) 745751.

[23] J.M. Candy, P.F. Nixon, R. England, G. Schenk, J. Koga, R.G. Duggleby, in: H. Bisswanger, A. Schellenberger (Eds.), Biochem. Physiol. Thiamin Diphosphate Enzymes, Proc. Int. Meet. 4th, A. u. C. Intemann Wiss. Verl., Prien, 1996, pp. 82-102.

[24] M. Killenberg-Jabs, S. König, I. Eberhardt, S. Hohmann, G. Hübner, Biochemistry 36 (1997) 1900-1905.

[25] G. Schenk, F.J. Leeper, P. England, R.G. Duggleby, Eur. J. Biochem. 248 (1997) 63-71.

[26] M. Pohl, P. Siegert, K. Mesch, H. Bruhn, J. Grötzinger, Eur. J. Biochem. 257 (1998) 538-546.

[27] A.K. Chang, P.F. Nixon, R.G. Duggleby, Biochem. J. 339 (1999) 255-260.

[28] M. Liu, E.A. Sergienko, F.S. Guo, J. Wang, K. Tittmann, G. Hübner, W. Furey, F. Jordan, Biochemistry 40 (2001) 7355-7368.

[29] E.A. Sergienko, F. Jordan, Biochemistry 40 (2001) 7369-7381.

[30] C.Y. Huang, A.K. Chang, P.F. Nixon, R.G. Duggleby, Eur. J. Biochem. 268 (2001) 3558-3565.

[31] D. Kern, G. Kern, H. Neef, K. Tittmann, M. Killenberg-Jabs, C. Wikner, G. Schneider, G. Hübner, Science 275 (1997) 67-70.

[32] K. Tittmann, R. Golbik, K. Uhlemann, L. Khailova, G. Schneider, M. Patel, F. Jordan, D.M. Chipman, R.G. Duggleby, G. Hübner, Biochemistry 42 (2003) 7885-7891.

[33] A. Schütz, R. Golbik, S. König, G. Hübner, K. Tittmann, Biochemistry 44 (2005) 6164-6179.

[34] A. Schellenberger, W. Rödel, Angew. Chem. 76 (1964) 226-2271964

[35] A. Schellenberger, K. Winter, Hoppe-Seylers Z. Physiol. Chem. 322 (1960) 164-172.

[36] A. Schellenberger, K. Winter, Hoppe-Seylers Z. Physiol. Chem. 344 (1966) $16-24$.

[37] A. Schellenberger, H. Hanke, G. Hübner, Hoppe-Seylers Z. Physiol. Chem. 349 (1968) 517-518.

[38] A. Schellenberger, I. Heinroth, G. Hübner, Hoppe-Seylers Z. Physiol. Chem. 348 (1967) 506-511.

[39] A. Schellenberger, G. Hübner, H. Neef, Methods Enzymol. 279 (1997) 131-146.
[40] A. Schellenberger, W. Rödel, H. Rödel, Hoppe-Seylers Z. Physiol. Chem. 339 (1964) 122-134.

[41] A. Schellenberger, H. Thieme, G. Hübner, Z. Chem. 9 (1969) 62.

[42] A. Schellenberger, K. Wendler, P. Creutzburg, G. Hübner, Hoppe-Seylers Z Physiol. Chem. 348 (1967) 501-505.

[43] H.J. Wittorf, C.J. Gubler, Eur. J. Biochem. 22 (1971) 544-550.

[44] H. Neef, R. Golbik, B. Fahlbusch, A. Schellenberger, Liebigs Ann. Chem. (1990) 913-916.

[45] H. Neef, K.D. Kohnert, A. Schellenberger, J. Prakt. Chem. 315 (1973) 701-710.

[46] R. Golbik, H. Neef, G. Hübner, S. König, B. Seliger, L. Meshalkina, A. Schellenberger, G.A. Kochetov, Bioorg. Chem. 19 (1991) 10-17.

[47] I. Tomita, S. Saitou, T. Ozawa, Biochem. Biophys. Res. Commun. 57 (1974) 78-84.

[48] S. Eppendorfer, S. König, R. Golbik, H. Neef, K. Lehle, R. Jaenicke, A. Schellenberger, G. Hübner, Biol. Chem. Hoppe-Seyler 374 (1993) 1129-1134.

[49] S. Mann, C.P. Melero, D. Hawksley, F.J. Leeper, Org. Biomol. Chem. 2 (2004) 1732-1741.

[50] K.M. Erixon, C.L. Dabalos, FJ. Leeper, Chem. Commun. 9 (2007) 960-962.

[51] R. Breslow, Ann. NY Acad. Sci. 98 (1962) 445-452.

[52] M.A. Lie, L. Celik, K.A. Jorgensen, B. Schiott, Biochemistry 44 (2005) 14792-14806.

[53] E. Joseph, W. Wei, K. Tittmann, F. Jordan, Biochemistry 45 (2006) 13517-13527.

[54] Y.G. Wu, A.K. Chang, P.F. Nixon, W. Li, R.G. Duggleby, Eur. J. Biochem. $267(2000)$ 6493-6500.

[55] D.J. Kuo, F. Jordan, Biochemistry 22 (1983) 3735-3739.

[56] X. Zeng, A. Chung, M. Haran, F. Jordan, J. Am. Chem. Soc. 113 (1991) 5842-5849.

[57] I. Baburina, H. Li, B. Bennion, W. Furey, F. Jordan, Biochemistry 37 (1998) 1235-1244.

[58] F.S. Guo, D.Q. Zhang, A. Kahyaoglu, R.S. Farid, F. Jordan, Biochemistry 37 (1998) 13379-13391.

[59] F. Jordan, FEBS Lett. 457 (1999) 298-301.

[60] F. Jordan, G. Chen, S. Nishikawa, B.S. Wu, Ann. NY Acad. Sci. 378 (1982) 14-31.

[61] I. Baburina, Y. Gao, Z. Hu, F. Jordan, S. Hohmann, W. Furey, Biochemistry 33 (1994) 5630-5635.

[62] I. Eberhardt, H. Cederberg, H. Li, S. König, F. Jordan, S. Hohmann, Eur. J. Biochem. 262 (1999) 191-201.

[63] H. Li, W. Furey, F. Jordan, Biochemistry 38 (1999) 9992-10003.

[64] H. Li, F. Jordan, Biochemistry 38 (1999) 10004-10012.

[65] D.D. Davies, Proc. Biochem. Soc. 104 (1967) 50P.

[66] G. Hübner, G. Fischer, A. Schellenberger, Z. Chem. 10 (1970) 436-437.

[67] A. Boiteux, B. Hess, FEBS Lett. 9 (1970) 293-296.

[68] J. Ullrich, I. Donner, Hoppe-Seylers Z. Physiol. Chem. 351 (1970) 1026-1029.

[69] G. Hübner, R. Weidhase, A. Schellenberger, Eur. J. Biochem. 92 (1978) 175-181.

[70] S. König, G. Hübner, A. Schellenberger, Biomed. Biochim. Acta 49 (1990) $465-471$.

[71] A. Dietrich, S. König, FEBS Lett. 400 (1997) 42-44.

[72] S. Bringer-Meyer, K.L. Schimz, H. Sahm, Arch. Microbiol. 146 (1986) 105-110.

[73] A. Schütz, R. Golbik, K. Tittmann, D.I. Svergun, M.H.J. Koch, G. Hübner, S. König, Eur. J. Biochem. 270 (2003) 2322-2331.

[74] A.I. Biryukov, V.I. Bunik, Y.N. Zhukov, E.N. Khurs, R.M. Khomutov, FEBS Lett 382 (1996) 167-170.

[75] V.I. Bunik, A.I. Biryukov, Y.N. Zhukov, FEBS Lett. 303 (1992) 197-201.

[76] R. Kluger, K. Nakaoka, Biochemistry 13 (1974) 910-914.

[77] R. Kluger, D.C. Pike, J. Am. Chem. Soc. 99 (1977) 4504-4506.

[78] T.A. O’Brien, R. Kluger, D.C. Pike, R.B. Gennis, Biochim. Biophys. Acta 613 (1980) 10-17.

[79] P. Arjunan, M. Sax, A. Brunskill, K. Chandrasekhar, N. Nemeria, S. Zhang, F. Jordan, W. Furey, J. Biol. Chem. 281 (2006) 15296-15303.

[80] A.K. Bera, L.S. Polovnikova, J. Roestamadji, T.S. Widlanski, G.L. Kenyon, M.J. McLeish, M.S. Hasson, J. Am. Chem. Soc. 129 (2007) 4120-4121.

[81] G. Wille, D. Meyer, A. Steinmetz, E. Hinze, R. Golbik, K. Tittmann, Nat. Chem. Biol. 2 (2006) 324-328.

[82] T. Brauner, J. Ullrich, Hoppe-Seylers Z. Physiol. Chem. 353 (1972) 825-831.

[83] G. Hübner, S. König, A. Schellenberger, Biomed. Biochim. Acta 47 (1988) 9-18

[84] J. Wang, R. Golbik, B. Seliger, M. Spinka, K. Tittmann, G. Hübner, F. Jordan, Biochemistry 40 (2001) 1755-1763.

[85] W. Wei, M. Liu, F. Jordan, Biochemistry 41 (2002) 451-461.

[86] W. Furey, P. Arjunan, L. Chen, F. Dyda, T. Umland, S. Swaminathan, M. Sax, F. Jordan, B. Farrenkopf, Y. Gao, D. Zhang, in: H. Bisswanger, A. Schellenberger (Eds.), Biochem. Physiol. Thiamin Diphosphate Enzymes, Proc. Int. Meet. 4th, A. u. C. Intemann Wiss. Verl., Prien, 1996, pp. 103-124.

[87] M. Killenberg-Jabs, A. Jabs, H. Lilie, R. Golbik, G. Hübner, Eur. J. Biochem. 268 (2001) 1698-1704.

[88] S. Kutter, M. Spinka, M.H.J. Koch, S. König, Prot. J. 26 (2007) 585-591.

[89] W. Furey, P. Arjunan, L. Chen, M. Sax, F. Guo, F. Jordan, Biochim. Biophys. Acta 1385 (1998) 253-270.

[90] F. Dyda, W. Furey, S. Swaminathan, M. Sax, B. Farrenkopf, F. Jordan, Biochemistry 32 (1993) 6165-6170.

[91] S. Kutter, G. Wille, S. Relle, M.S. Weiss, G. Hübner, S. König, FEBS J. 273 (2006) 4199-4209.

[92] D. Dobritzsch, S. König, G. Schneider, G. Lu, J. Biol. Chem. 273 (1998) 20196-20204.

[93] A. Schütz, T. Sandalova, S. Ricagno, G. Hübner, S. König, G. Schneider, Eur. J Biochem. 270 (2003) 2312-2321.

[94] Y.A. Muller, Y. Lindqvist, W. Furey, G.E. Schulz, F. Jordan, G. Schneider, Structure 1 (1993) 95-103. 
[95] J. Pletcher, M. Sax, A. Turano, C.H. Chang, Ann. NY Acad. Sci. 378 (1982) 454-458.

[96] C.F. Hawkins, A. Borges, R.N. Perham, FEBS Lett. 255 (1989) 77-82.

[97] G. Hübner, S. König, A. Schellenberger, M.H.J. Koch, FEBS Lett. 266 (1990) 17-20.

[98] M.W. Washabaugh, W.P. Jencks, Biochemistry 27 (1988) 5044-5053.
[99] J. Crosby, G.E. Lienhard, J. Am. Chem. Soc. 92 (1970) 5707-5716

[100] F.J. Alvarez, J. Ermer, G. Hübner, A. Schellenberger, R.L. Schowen, J. Am. Chem. Soc. 117 (1995) 1678-1683.

[101] S.X. Sun, R.G. Duggleby, R.L. Schowen, J. Am. Chem. Soc. 117 (1995) 7317-7322 [102] C. Frieden, J. Biol. Chem. 245 (1970) 5788-5799. 